\title{
The Content and Enlightenment of the National Core Arts Standards of the United States
}

\author{
Mengjia Zhang \\ Tianxinghu High School, Nantong 210023, Jiangsu, China \\ Email: zmjmusic@sina.com
}

\begin{abstract}
In 2014, the National Coalition for Core Arts Standards published the revised National Core Arts Standards. It was jointly drawn up by five writing teams of music, media arts, dance, theatre and visual arts. This paper will focus on the content and the structure of the Standards in order to provide a broad international perspective and inspire front-line teachers.
\end{abstract}

Keywords: the National Core Arts Standards, art education

\section{Introduction}

The structure of the National Core Arts Standards (hereinafter referred to as the 2014 Standards) suggests that the core is to ensure that all students receive a comprehensive education. Therefore, philosophical foundations, lifelong goals, artistic processes, creative practices, student achievement anchoring and performance standards, and model cornerstone assessments are included in an overall conceptual framework to guide the design, teaching and evaluation of the art curriculum in American schools.

\section{The main content of the 2014 Standards}

The 2014 Standards set forth new benchmarks for art learning, aiming to provide all students with a comprehensive and balanced education. Next, this paper will analyze the specific content of the 2014 Standards.

\subsection{Background and philosophy}

The importance of art education was recognized by American schools in the early 19th century. Since then, people looked forward to clarifying what students should know and do through legislation.

In 1994, the National Standards for Art Education (hereinafter referred to as the 1994 Standards) was released. It provided practical goals and requirements for each stage of school art education from kindergarten to Grade 12.

In the 20 years after the release and implementation of the 1994 Standards, many states experienced great changes in economic development, political situations, and educational practices. In order to improve the quality of the Standards, the National Coalition for Core Arts Standards reconstructed and revised the Standards on the basis of the 1994 Standards and the Dance Standards. In June 2014, the 2014 Standards was published online, and the basic ideas consisted of philosophical foundations and lifelong goals.

\subsection{Goals and framework}

The art framework of the 2014 Standards takes the method of Backward Design, which is mainly reflected in the process expressions common to the five art disciplines - four processes, eleven anchor standards and performance standards from pre-kindergarten to high school. 
Table 1. The Framework of the National Core Arts Standards

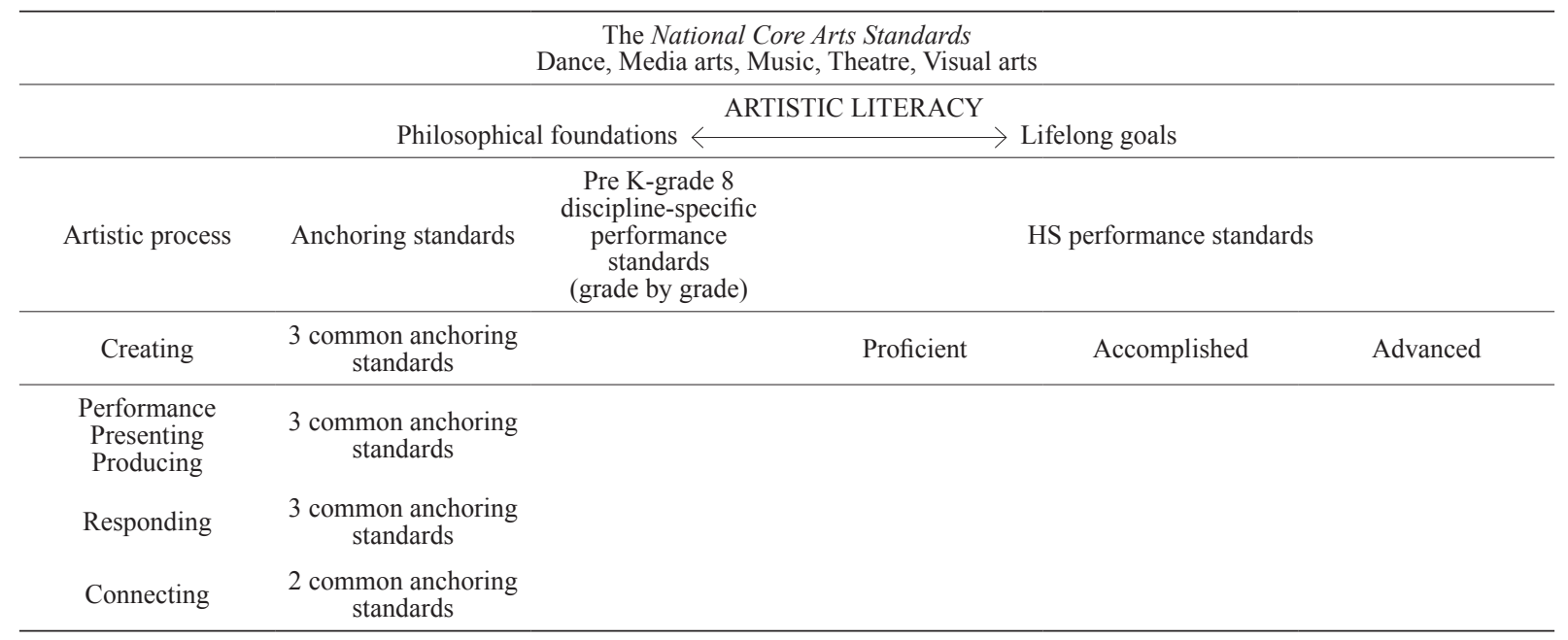

(Source: http://www.nationalartsstandards.org ${ }^{[1]}$ )

According to Table 1, we can get some information as followed.

First, the 2014 Standards is divided into different stages according to age. From pre-kindergarten to Grade 8 , general music courses are set for different grades.

Different courses are offered to students from Grade 9 to Grade 12, which not only meets the needs of students who have laid a solid foundation in the first stage and are interested in pursuing a deeper level in a certain art subject, but also meets the desire of students who would like to extensively explore and pursue multi-disciplinary artistic experience. The performance standards are divided into three levels: proficient, accomplished, and advanced.

Second, the 2014 Standards attaches great importance to the process of art learning and regards it as the most important part of evaluating student learning. This is because although each art discipline has its own characteristics, it includes the artistic process of Creating, Performance, Presenting, Producing and Responding in some way. For this reason, the 2014 Standards stipulates four artistic processes for each subject according to the characteristics of different disciplines, with two or three common anchor standards for each process. These standards are parallel to the various art disciplines and grade levels, and are practical and educational expressions of artistic literacy in the Standards.

\subsection{Curriculum and implementation}

Backward Design, also called Task-oriented Teaching, is a basic teaching method in the National Core Music Standards. It was proposed by Jay McTighe and Grant Wiggins in Understanding by Design in $1998^{[2]}$.

As a task-oriented curriculum design method, its main content is to help teachers set teaching goals when choosing teaching methods and assessment types. It mainly includes three parts: determination of the expected results, determination of the acceptable level of evidence supporting the expected results, and design of the best activities to make the desired results occur. Although the National Core Arts Standards is result-oriented, the formulation still takes into account the balance between the existing structure and the ideal structure of American schools.

In addition, the 2014 Standards provides teachers with a detailed model for basic evaluation, with which teachers can make formative assessments of students and help them develop music literacy.

\section{Analysis and reflection on the Music Standards of high schools}

The Music Standards are designed to guide music teachers to achieve the expected results through the artistic process, thereby facilitating continuous teaching. What are the content and evaluation standards of Chinese and American high school music curriculum?

The 2014 Standards sets three levels (proficient, accomplished, and advanced) for four different courses offered to high school students: Music Theory and Composition, Traditional and Emerging Music Ensemble, Harmony Instrumental Music and Music Technology.

The General High School Curriculum Standards (2017 Edition) issued by the Ministry of Education of the People's 
Republic of China pointed out that music courses of general high schools consist of three types of courses (compulsory courses, optional compulsory courses, and elective courses), whose academic quality can be divided into three levels ${ }^{[3]}$. After completing the corresponding class hours, students can obtain corresponding credits by passing tests at different levels.

The compulsory courses include six modules, music appreciation, singing, performance, music creation, music and dance, and music and theatre. Schools can start classes by class or enable students to select the classes. The elective compulsory courses include six modules. chorus, ensemble, dance performance, drama performance, basic music theory, and ear training. Teaching can be organized at three levels, classes, grades, and art clubs. Elective courses are flexibly offered by the school based on the school's philosophy and other factors.

In terms of the course content, both countries have set up courses in composition and instrumental ensemble at the high school level, which are comprehensive in nature. To be specific, China has established interdisciplinary communication and fusion in the module of Music Appreciation, which closely connects music with poetry, science, and history, while the Music Technology offered by American schools is an interdisciplinary course of music and science and technology, including various research and application areas.

In terms of course positioning, music is a compulsory course in both countries. The 2000 Goal: Educate America Act passed the legislative process, writing arts into the federal law ${ }^{[4]}$. This decree recognizes that art is a core discipline and has the same important status as other disciplines in education. Therefore, the music course is a compulsory course for American students. In China, the music course is also a compulsory course for all high school students, and it is irreplaceable for the overall development of students. However, some regulations issued by the state have not yet been fully implemented, and some issues need to be continuously improved.

From curriculum evaluation, the cornerstone evaluation adopted in the United States is a curriculum-embedded evaluation method, which is different from out-of-context and multiple-choice test evaluations, while China combines formative evaluation with summative evaluation, combines qualitative evaluation with quantitative evaluation, and combines self-evaluation, mutual evaluation with other evaluations.

\section{Enlightenment}

The Ministry of Education of our country pointed out: "We must give full play to the unique educational advantages of the humanities, follow the latest developments in foreign curriculum reforms, and learn from international experience." The National Core Arts Standards presents us with a method of art education method that focuses on thinking process, lasting understanding, key issues and alternative assessment, which is quite novel and innovative. First, it emphasizes the development of "big ideas" and students' "lasting understanding". Second, it takes Backward Design and provides new ideas for teaching design. Third, it focuses on the application of science and technology in art. Fourth, it applies the cornerstone assessments of formative evaluation and summative evaluation.

Based on the reality of education in China and it can be seen that the 2014 Standards is of important value for reference. We can not only learn from the educational concepts in the 2014 Standards, but also continue to dig, inherit and carry forward the excellent Chinese cultural traditions with an international perspective. These tasks will surely become the stepping stones of China's future music education.

\section{References}

[1] National Core Arts Standards[O/L]. Available from: http://www.nationalartsstandards.org.

[2] Xu Ting. (2016) Research on the Curriculum Design Concept and Music Curriculum Standards of American National Core Art Standards. China Conservatory of Music, Beijing.

[3] Ministry of Education of the People's Republic of China. Standards for music curriculum for general high school (2017 edition and 2020 revision). Beijing: People's Education Press; 2017.

[4] Qiu Zhijun. Comparison and thinking on the "Art Curriculum Standards" between China and the United States. New Curriculum (Part 2). 2011; (01): 9. 